\title{
REDUCING ENERGY CONSUMPTION IN COLD STORES USING A \\ FREELY AVAILABLE MATHEMATICAL MODEL
}

\author{
A.M. FOSTER ${ }^{1 *}$, L.O. REINHOLDT ${ }^{2}$, T. BROWN ${ }^{1}$, E.C. HAMMOND ${ }^{1}$ and J.A. EVANS ${ }^{1}$ \\ ${ }^{1 *}$ London South Bank University, Langford, North Somerset, UK,+44 1179289281, \\ $\underline{\text { alan.foster@1sbu.ac.uk }}$ \\ ${ }^{2}$ Danish Teknologisk Institut, Kongsvang Allé 29, 8000 Aarhus C, Denmark.
}

\begin{abstract}
The ICE-E model is a user-friendly tool that allows cold store operators to predict the energy consumption of their stores as heat loads vary due to changes in ambient conditions and store usage patterns. Weather data and construction and usage details are used to predict heat load and refrigeration COP on an hourly basis over a whole year. The model was validated against the industry standard CoolPack model and the features of the models were compared. The ICE-E model is better suited to non-technical cold store users who may not know details such as U-values, air change rates, respiration rates, condensing and evaporating temperatures, and it has additional features such as the ability to change efficiencies of lights and fans. It can help users to identify which cold store features and operating parameters have the greatest impact on energy consumption, and assess the scope for measures aimed at reducing it.
\end{abstract}

\section{Keywords}

Energy, cold storage, numerical modelling, heat loads, audits, transient 


\section{NOMENCLATURE}

A surface area $\left(\mathrm{m}^{2}\right)$

e $\quad$ efficacy of lighting lamps $\left(1 \mathrm{~m} . \mathrm{W}^{-1}\right)$

COP coefficient of performance of the compressor

E effectiveness of door protection or blockage

EL Elevation (radians)

d day of year (integer)

F density factor

g acceleration due to gravity $\left(9.81 \mathrm{~m} . \mathrm{s}^{-2}\right)$

h heat transfer coefficient $\left(\mathrm{W} \cdot \mathrm{m}^{-2} \cdot \mathrm{K}^{-1}\right)$

$\mathrm{H} \quad$ height of cold store door $(\mathrm{m})$

HRA Hour angle (radians)

I ratio of solar radiation incident on each of the cold store walls at an angle to the sun to that normal to the sun (ratio)

$\mathrm{k} \quad$ thermal conductivity $\left(\mathrm{W} \cdot \mathrm{m}^{-1} \cdot \mathrm{K}^{-1}\right)$

$1 \quad$ latent heat of fusion for water $\left(\mathrm{J}^{\mathrm{kg}} \mathrm{g}^{-1}\right)$

$\mathrm{L} \quad$ length of door seals (m)

LF luminous flux (lm. $\left.\mathrm{m}^{-2}\right)$

LST Local solar time

$\mathrm{m}$ mass flow rate $\left(\mathrm{kg} . \mathrm{s}^{-1}\right)$

n stage coefficient

$\mathrm{N}$ number

M Mass loaded per day (kg.day $\left.{ }^{-1}\right)$ 
P electrical power (W)

q heat flow per unit area $\left(W \cdot m^{-2}\right)$

Q heat flow (W)

$\mathrm{r} \quad$ proportion of solar radiation incident on surface (ratio)

$\mathrm{t} \quad$ duration (s)

S Shaft power (W)

T temperature $\left({ }^{\circ} \mathrm{C}\right)$

$\mathrm{U} \quad$ overall heat transfer coefficient $\left(\mathrm{W} . \mathrm{m}^{-2} . \mathrm{K}\right)$

$\mathrm{v} \quad$ volume flow rate through seals per metre of seal length $\left(\mathrm{m}^{2} \cdot \mathrm{s}^{-1}\right)$

$\mathrm{V} \quad$ wind speed $\left(\mathrm{m} \cdot \mathrm{s}^{-1}\right)$

$\mathrm{x}$ fractional vaporisation of refrigerant in evaporator on expansion from liquid to saturation at discharge

$\mathrm{X} \quad$ concentration of water in air

$\alpha \quad$ empirical constant for different refrigerants

$\delta \quad$ declination angle (degrees)

$\Delta \quad$ thickness (m)

$\rho \quad$ density $\left(\mathrm{kg} \cdot \mathrm{m}^{-3}\right)$

$\mu \quad$ efficiency

$\varphi \quad$ latitude

Subscripts

24 in 24 hours 
ad air through door

c condensing

comp compressor

cond condenser

d door

do door opening

ds door seals

de defrost

e evaporating

f floor

fl fork lifts

fu fusion

i inside

$1 \quad$ lights

me evaporator fan motor

mc condenser fan motor

o outside

ot other

pe personnel

pr product

r respiration

s solar

$\mathrm{T}$ total

v vapour

w wall

wp water from product/packaging 


\section{INTRODUCTION}

Food cold store facilities generally store food at chilled temperatures (typically between -1 and $5^{\circ} \mathrm{C}$ ) or frozen temperatures (typically below $-18^{\circ} \mathrm{C}$ ) to maintain quality and safety of the food. For some specialised products ultra-low temperatures (some fish, and specialised foods) or modified atmosphere storage (fruits and vegetables) are used. All chilled and frozen food and temperature controlled pharmaceutical products are stored in a cold store at least once during their journey from production to the consumer. In 2012 in Europe there were approximately 1.6 million cold stores, of which $67 \%$ were small stores with a volume of less than $400 \mathrm{~m}^{3}$ (Mudgal et al, 2011).

Cold storage rooms consume considerable amounts of energy. In 2002 the IIR estimated that the Specific Energy Consumption (SEC) of cold stores was between 30 and $50 \mathrm{kWh} \cdot \mathrm{m}^{-3} \cdot \mathrm{year}^{-1}$ (Duiven and Binard, 2002). The minimum value from this study was similar to values from a study carried out in the Netherlands by Bosma (1995) which found the average energy consumption of cold stores to be $35 \mathrm{kWh} . \mathrm{m}^{-3}$.year. In the UK, Energy Technology Support Unit (ETSU, 1994) also found that stores consumed at minimum 34 $\mathrm{kWh} / \mathrm{m}^{3} /$ year but that consumption could also be up to $124 \mathrm{kWh} / \mathrm{m}^{3} /$ year. Other studies in the USA by Elleson and Freund (2004) and Singh (2006) found SECs of between 19 and 88, and 15 and 132 $\mathrm{kWh} / \mathrm{m}^{3} / \mathrm{year}$ respectively. In one of the most comprehensive recent surveys, carried out in New Zealand by Werner et al (2006), the performance of 34 cold stores was compared. The SECs recorded varied from 26 to $379 \mathrm{kWh} / \mathrm{m}^{3} /$ year and savings of between 15 and $26 \%$ were found to be achievable by applying best practice technologies. Evans et al (2013) showed that considerable savings (between 8 and 72\%) could be made by optimising usage of stores, repairing current equipment and by retrofitting energy efficient equipment with relatively short payback periods (the majority being less than 3 years).

Much of the information provided to cold store end users is generic (reduce condensing temperature, increase evaporating temperature etc.) and little is specifically tailored to end users' particular needs. This was found to be a particular problem in audits carried out by Evans et al (2013) where options to reduce energy in cold stores varied widely between stores. Most energy saving options were only selected and 
installed after a case had been made for a relatively short payback period. This often required a level of knowledge not possessed by most cold store operators. It was therefore difficult for cold store operators to obtain a clear and unbiased view on whether energy saving options would be worthwhile in terms of carbon and financial savings.

There are a number of openly available simulation models designed specifically to model the performance of refrigeration systems. Most of these are aimed at retail refrigeration and include SuperSIM (Ge and Tassou, 2000), ORNL Supermarket spreadsheets (Baxter, 2003), Getu \& Bansal model LT-case (Getu and Bansal, 2006) the EKS program (Saint Trofee), RETScreen (Natural Resources Canada), EnergyPlus (US-DOE, 2010) and Cybermart (Arias et al, 2010). There are also specific programs for refrigeration systems and cycles, e.g. CoolPack and Pack Calculation, (IPU, Denmark).

Becker et al (2012) analysed the capabilities of CoolPack and Pack Calculation II to determine the energy efficiency of walk-in cooler and freezer refrigeration systems as a function of the ambient dry-bulb and wetbulb temperatures surrounding the walk-in and its condensing unit. They found that CoolPack was not capable of simulating the performance of a refrigeration system whose load varies according to ambient conditions that vary with the weather. Pack Calculation II cannot model a temperature-dependent refrigeration load so the effects of weather data on refrigeration load (conduction and infiltration) are ignored.

This paper presents a new user-friendly tool (ICE-E model) that allows cold store operators and technicians to predict cold store energy consumption when refrigeration load varies according to ambient weather conditions. The model was verified and compared with the industry standard CoolPack model. Weather data was used to predict both heat load and refrigeration COP through the whole year at 3 different locations in the world. The accuracy of using mean ambient weather conditions compared to varying annual weather was investigated using the ICE-E model.

\section{MODEL DESCRIPTION}

A spreadsheet-based mathematical model with Visual Basic macros (referred to as the ICE-E model) was developed in Microsoft Excel ${ }^{\mathrm{TM}}$. To operate the model the user was required to input data about the cold 
store as shown in

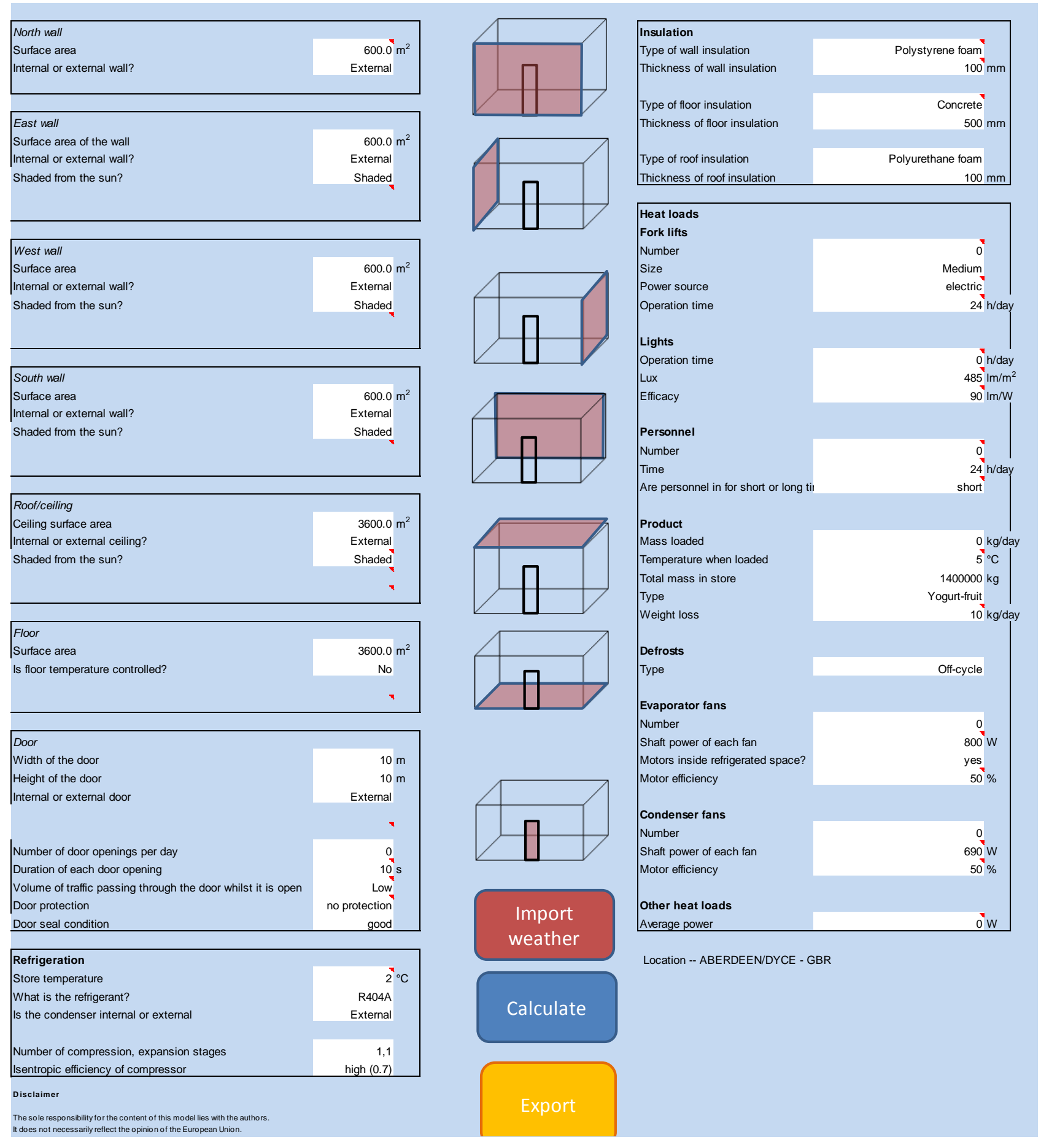

Figure 1. A detailed list of the parameters is shown in Table 1.

Table 1. List of the parameters used in the model.

\begin{tabular}{|l|l|}
\hline \multicolumn{1}{|c|}{ Parameter } & Details \\
\hline Geometry & \\
\hline
\end{tabular}




\begin{tabular}{|c|c|}
\hline Wall surface area $(\mathrm{N}, \mathrm{E}, \mathrm{W}, \mathrm{S})$ & $\mathrm{m}^{2}$ \\
\hline Internal or external & $\begin{array}{l}\text { IF internal THEN enter temperature adjacent to wall } \\
\text { IF external THEN temperature from weather data }\end{array}$ \\
\hline Shaded from sun & $\begin{array}{l}\text { IF yes THEN emissivity }=0 \\
\text { IF no THEN enter colour of wall (assigns an } \\
\text { emissivity) }\end{array}$ \\
\hline Is floor temperature controlled & $\begin{array}{l}\text { IF No THEN temperature from weather data } \\
\text { IF yes THEN enter temperature controlled to } \\
\text { IF yes THEN insert floor heating average electrical } \\
\text { power (W) }\end{array}$ \\
\hline \multicolumn{2}{|l|}{ Entrance } \\
\hline Width of door & $\mathrm{m}$ \\
\hline Height of door & $\mathrm{m}$ \\
\hline Internal or external door & $\begin{array}{l}\text { IF internal THEN insert temperature and RH outside } \\
\text { of the door } \\
\text { IF external THEN use weather data }\end{array}$ \\
\hline \multicolumn{2}{|l|}{ Number of door openings per day } \\
\hline Duration of each opening & $\mathrm{s}$ \\
\hline $\begin{array}{l}\text { Volume of traffic passing through the door whilst it is } \\
\text { open }\end{array}$ & $\begin{array}{l}\text { Low, medium or high (provides a different } \\
\text { effectiveness through door) }\end{array}$ \\
\hline Door protection & $\begin{array}{l}\text { Strip curtain, no protection or air curtain (provides a } \\
\text { different effectiveness through door) }\end{array}$ \\
\hline Door seal condition & $\begin{array}{l}\text { Bad or good (provides a different leakage rate per } \\
\text { meter length of seal) }\end{array}$ \\
\hline \multicolumn{2}{|l|}{ Refrigeration } \\
\hline Store temperature & ${ }^{\circ} \mathrm{C}$ \\
\hline Refrigerant & R717, R22, R404a, R134a \\
\hline Is the condenser internal or external? & $\begin{array}{l}\text { IF internal THEN enter ambient temperature } \\
\text { IF external THEN temperature from weather data }\end{array}$ \\
\hline
\end{tabular}




\begin{tabular}{|c|c|}
\hline Number of compression, expansion stages & 1 to 3 compression and expansion stages \\
\hline Isentropic efficiency of compressor & Low, medium or high \\
\hline \multicolumn{2}{|l|}{ Insulation } \\
\hline Type of insulation (wall, floor and ceiling) & $\begin{array}{l}\text { Polystyrene foam, Polyurethane foam, Glass, fibre, } \\
\text { Concrete, Corkboard, Polyisocyanurate, VIP (provides } \\
\text { the conductivity) }\end{array}$ \\
\hline Thickness of insulation (wall, floor and roof) & $\mathrm{mm}$ \\
\hline \multicolumn{2}{|l|}{ Fork lift trucks } \\
\hline \multicolumn{2}{|l|}{ Number } \\
\hline Size & Small, medium, large (provides the heat load) \\
\hline Power source & $\begin{array}{l}\text { electric or internal combustion (provides the heat load } \\
\text { in combination with the size) }\end{array}$ \\
\hline Operation time & $\mathrm{h} /$ day \\
\hline \multicolumn{2}{|l|}{ Lights } \\
\hline Operation time & h/day \\
\hline Lux & $\mathrm{lm} / \mathrm{m}^{2}$ \\
\hline Efficacy & $\mathrm{lm} / \mathrm{W}$ \\
\hline \multicolumn{2}{|l|}{ Personnel } \\
\hline \multicolumn{2}{|l|}{ Number } \\
\hline Time & h/day \\
\hline Are personnel in for short or long time? & Short or long (provides the heat output for personnel) \\
\hline \multicolumn{2}{|l|}{ Product } \\
\hline Mass loaded & $\mathrm{Kg} /$ day \\
\hline Temperature when loaded & ${ }^{\circ} \mathrm{C}$ \\
\hline Total mass in store & $\mathrm{Kg}$ \\
\hline Type & $\begin{array}{l}\text { List of products - provides specific heat capacity and } \\
\text { respiration coefficients for each product }\end{array}$ \\
\hline Weight loss & $\mathrm{Kg} /$ day \\
\hline Defrost & \\
\hline
\end{tabular}




\begin{tabular}{|c|c|}
\hline Type & $\begin{array}{l}\text { Electric, gas, off-cycle (provides the efficiency of } \\
\text { defrost) }\end{array}$ \\
\hline \multicolumn{2}{|l|}{ Evaporator fans } \\
\hline \multicolumn{2}{|l|}{ Number } \\
\hline Shaft power & $\mathrm{W}$ \\
\hline Motors inside refrigerated space? & Yes or no \\
\hline motor efficiency & $\%$ \\
\hline \multicolumn{2}{|l|}{ Condenser fans } \\
\hline \multicolumn{2}{|l|}{ Number } \\
\hline Shaft power & W \\
\hline motor efficiency & $\%$ \\
\hline Other heat loads average power & W \\
\hline Import weather & $\begin{array}{l}\text { Air temperature, } \mathrm{RH} \text {, ground temperature, wind speed, } \\
\text { solar radiation every hour at locations throughout the } \\
\text { world }\end{array}$ \\
\hline Calculate & Calculates the electrical power every hour for the year \\
\hline Export & $\begin{array}{l}\text { Exports heat loads in a format where they can be } \\
\text { entered into Pack-Calculation II }\end{array}$ \\
\hline
\end{tabular}

Energy consumption was calculated every hour for a whole year. External heat loads from ambient were calculated every hour based on historical local weather data imported from the U.S. Department of Energy, EnergyPlus Energy Simulation Software, weather database.

(http://apps1.eere.energy.gov/buildings/energyplus/cfm/weather data.cfm).

The ambient parameters which changed every hour were the ambient temperature, relative humidity (RH), ground temperature, wind speed, solar radiation and the position of the sun in the sky. All other heat loads were averaged throughout the year. Refrigeration condenser ambient conditions were also calculated from the hourly weather data. This allowed a yearly profile of energy consumption to be evaluated. 
The daily heat loads for each month of one year were shown as a bar graph. The hourly heat loads during the day for the months of the year were shown as a line graph. A similar output was then presented for electrical consumption and power.

If the refrigeration model was not adequate (due to complexity of the system) the hourly heat loads could be exported via another macro accessed by an 'Export' macro. These heat loads could be imported into PackCalculation II (IPU Technology Development, Denmark). Pack Calculation is an application for comparing the yearly energy consumption of refrigeration plants. The application contains models of 11 commonly used refrigeration cycles and more than 4000 commercially available compressors (http://www.en.ipu.dk/indhold/refrigeration-and-energy-technology/pack-calculation-ii/pack-calculationii.aspx 


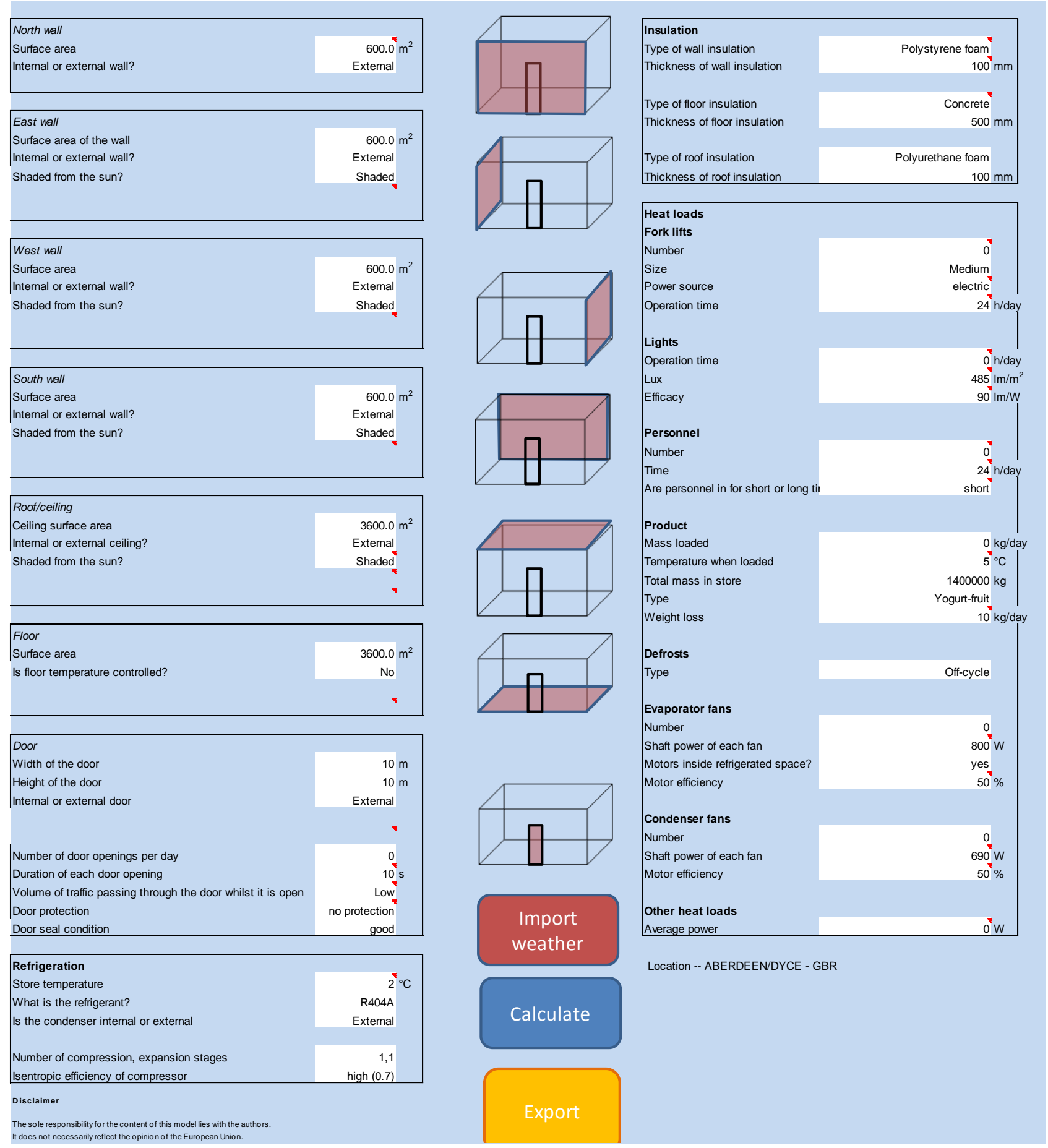

Figure 1. Spreadsheet input form.

\subsection{Heat loads}

The total heat load, $\mathrm{q}_{\mathrm{T}}$, on the cold store is given by

$$
Q_{T}=Q_{w}+Q_{d o}+Q_{p e}+Q_{f l}+Q_{p r}+Q_{m e}+Q_{d e}+Q_{l}+Q_{f}+Q_{o t}+Q_{r}
$$


The shape of the cold store was a rectangular box. The heat load through the cold store walls was calculated using (2)

$$
Q_{w}=U \cdot A_{w} \cdot\left(T_{0}-T_{i}+T_{s}\right)
$$

The overall heat transfer coefficient, $\mathrm{U}$ was calculated using (3).

$$
\frac{1}{U}=\frac{1}{h_{i}}+\frac{1}{h_{o}}+\frac{\Delta_{w}}{k_{w}}
$$

Cold store walls are usually a modular construction, with an insulating inner and thin outer cladding. The outer cladding has a negligible effect on the $\mathrm{U}$ value so can be ignored. A surface heat transfer coefficient of $9.3 \mathrm{~W} \cdot \mathrm{m}^{-2} \cdot \mathrm{K}^{-1}$ was used for $\mathrm{h}_{\mathrm{i}}\left(\right.$ ASHRAE, 2001). The heat transfer coefficient outside the cold store, $\mathrm{h}_{\mathrm{o}}$ was related to the wind speed outside (unless the outside wall adjoined another building, in which case it was set to be $\mathrm{h}_{\mathrm{i}}$ ), using the simplified equation for forced air of less than $5 \mathrm{~m} \cdot \mathrm{s}^{-1}$ at room temperature (4) (McAdams, 1954) .

$$
h_{o}=5.62+3.9 \cdot V
$$

The wind speed came from the daily average wind speed for each month, from the weather data.

The solar temperature $T_{s}$ was an adjustment to compensate for solar effect on heat load and is described in (5).

$$
T_{s}=\frac{q_{s} \cdot r}{h_{o}}
$$

Where $\mathrm{q}_{\mathrm{s}}$ is the solar radiation on the surface and $\mathrm{r}$ the proportion of solar energy transmitted on each surface. Average hourly statistics for direct normal solar radiation were provided in the imported weather data file.

This radiation was not evenly distributed over all of the surfaces (walls and roof) of the cold store, instead the distribution of solar radiation changed throughout the day as the sun rose and set in the sky. To approximate the proportion of solar energy, $r$, transmitted on each surface (east, west, south and north roof) the following equation was used 


$$
r_{x}=\frac{I_{x}}{I_{w}+I_{e}+I_{s}+I_{n}+I_{r}}
$$

Where $\mathrm{x}=\mathrm{w}, \mathrm{e}, \mathrm{s}, \mathrm{n}$ or $\mathrm{r}$ for each of the west, east, south and north walls and the roof

For each wall, the ratio of solar radiation incident at an angle to the sun to that normal to the sun, I, was calculated from;

$$
\begin{aligned}
& I_{e}=-\sin (H R A) \\
& I_{w}=\sin (H R A) \\
& I_{n}=0 \\
& I_{s}=\sin (90-E L) \\
& I_{r}=\sin (E L)
\end{aligned}
$$

A simplistic approach to estimating the amount of solar radiation on each of the cold store walls was to consider the sun's position in the sky relative to the East-West axis and South-North axis. It was considered that the sun travelled from East to West according to the hour angle HRA as shown in (12),

$$
H R A=15 \cdot(L S T-12)
$$

It was also considered that the angle in the sky on the South-North axis was equal to the solar elevation angle, EL. This is the angle between the horizon and the centre of the sun's disc (13). If elevation $<=0$ then solar radiation $=0$ (night time).

$$
E L=\sin ^{-1}[\sin \delta \sin \varphi+\cos \delta \cos \varphi \cos (H R A)]
$$

The latitude, $\varphi$ is taken from the location in the weather input file.

The declination angle, $\delta$ is calculated in (14), where 23.45 is the angle of tilt of the Earth's axis.

$$
\delta=23.45 \cdot \sin \left[\frac{360}{365}(d-81)\right]
$$

The cold room was assumed to only have 1 door and the room was otherwise fully sealed. The assumption was made that the cold store had sufficient thermal mass so that door openings did not change the 
temperature within the cold store. The temperature of the ambient air outside the cold store was not changed by the door openings.

The heat load through the door opening, $\mathrm{Q}_{\mathrm{do}}$, was calculated using the sensible and latent heat exchange caused by mass flow of air during door opening and through the seals when the door was closed (15). The additional sensible heat of water vapour was ignored, as the specific moisture content is generally less than $1 \%$. The latent heat of fusion, $\mathrm{l}_{\mathrm{fu}}=0$ when the evaporating temperature $>0{ }^{\circ} \mathrm{C}$.

$$
Q_{d o}=\left(m_{d o}+m_{d s}\right) \cdot\left[c_{p}\left(T_{o}-T_{i}\right)+\left(X_{o}-X_{i}\right) \cdot\left(l_{f u}+l_{v}\right)\right] \cdot t_{d o} \cdot \frac{N_{d o}}{(24 \cdot 3600)}
$$

The mass flow through an open door was calculated using the Gosney and Olama model (1975) (16). An effectiveness value was used to reduce the infiltration for door protection devices and traffic obstructing the opening as detailed by Chen et al (2002).

$$
m_{d o}=(1-E) \cdot 0.221 \cdot A_{d} \rho_{i}\left(1-\frac{\rho_{o}}{\rho_{i}}\right)^{0.5}(g \cdot H)^{0.5} \cdot F
$$

The density factor was calculated according to

$$
F=\left(\frac{2}{1+\left(\frac{\rho_{i}}{\rho_{o}}\right)^{0.333}}\right)^{1.5}
$$

The mass flow through the door seal was calculated using (18). The model had two defaults values for volume flow rate through seals, v. These were 0.003 and $0.0006 \mathrm{~m}^{3} \cdot \mathrm{s}^{-1}$ per metre of seal length for a bad and good seal respectively. These values were the extreme values presented by Cleland (2011).

$$
m_{d s}=v \cdot \rho \cdot L
$$

The heat load due to personnel in the store was calculated using the following equation (ASHRAE, 2006a).

$$
Q_{p e}=272-6 \cdot \mathrm{T}_{\mathrm{i}}
$$


When people first enter the cold room they bring in additional surface heat. Thus, when many people enter and leave every few minutes, the load is greater than that in (19). If personnel enter and leave frequently (an option which is available to the user), the values calculated in Equation (19) are multiplied by 1.25 (ASHRAE, 2006a).

The thermal mass of fork lift trucks was ignored and therefore if they moved from a warm environment into the store, they did not give up this heat to the store. Energy from fork lift trucks did not include any charging of the batteries within the cold store. The heat load from fork lift trucks was calculated using (20). The model provided values for small, medium or large trucks which were electrically or internal combustion powered.

$$
Q_{f l}=\frac{N_{f l, 24} \cdot P_{f l} \cdot t_{f l}}{24 \cdot 3600}
$$

The product load was calculated from the mass of product entering the store every 24 hours $\left(\mathrm{M}_{\mathrm{pr}}\right)$ and the temeprature difference between the product when it entered the store $\left(\mathrm{T}_{\mathrm{pr}}\right)$ and the temperature of the store $\left(\mathrm{T}_{\mathrm{i}}\right)$. Therefore it was assumed that all heat was removed from the product in 24 hours and that there was no latent heat from the product. Specific heat values were contained within the model for 69 different products and were calulated using the COSTHERM program (Miles et al, 1983). Heat required to freeze the water evaporated from the product/packaging $\left(\mathrm{M}_{\mathrm{wp}} .1\right)$ is only condsidered for chill stores where the evaporator is less than $0^{\circ} \mathrm{C}$.

$$
Q_{p r}=\frac{M_{p r} \cdot c_{p}\left(T_{p r}-T_{i}\right)+\left(M_{W p} \cdot l\right)}{24 \cdot 3600}
$$

Heat of respiration, $\mathrm{Q}_{\mathrm{r}}$, was calculated using (22)

$$
Q_{r}=a \cdot e^{T i_{i} b}
$$

Where $a$ and $b$ are respiration coefficients derived from line fits using data from ASHRAE (2006b)

The heat load of the evaporator fan motors, $\mathrm{Q}_{\mathrm{me}}$ is given in (23). Where the electric motor was mounted outside of the cold store, $\mu_{m e}=1$. 


$$
Q_{m e}=\frac{N_{m e} \cdot S}{\mu_{m e}}
$$

The heat load from defrosting evaporators was equal to the amount of heat required to melt all the frozen water which entered the room through the doorway and from product/packaging divided by the efficiency of defrost minus the heat of water leaving through the condensate drain as in the following equation.

$$
Q_{d e}=\left(\frac{1}{\mu_{d e}}-1\right) \cdot\left(\frac{m_{a d} \cdot\left(X_{o}-X_{i}\right) \cdot l \cdot t \cdot N_{d o, 24}+\left(M_{w p} . l\right)}{24 \cdot 3600}\right)
$$

The efficiency of defrost, $\mu_{\mathrm{de}}$, is defined as the energy required to melt the ice divided by the energy input by the defrost. Therefore, if the efficiency of defrost was 0.5 , twice as much energy as needed would be used to melt the ice.

The heat load from the lights was calculated from the luminous flux distributed evenly over the floor and walls divided by the efficacy of the lamps. The time the lights were on was averaged over 24 hours.

$$
Q_{l}=\frac{P_{l} \cdot t_{l}}{24}
$$

Where

$$
P_{l}=\frac{\operatorname{LF}\left(A_{f}+A_{w}\right)}{e_{l}}
$$

Heat loads for other electrical loads were equal to the electrical loads.

$$
Q_{o t}=E_{o t}
$$

\subsection{Electrical power}

The total electrical power was the sum of all the electrical loads as given in the following equation.

$$
P_{T}=P_{c o m p}+P_{d e}+P_{l}+P_{m c}+P_{m e}+P_{f}+P_{o t}
$$

An electrical energy of the compressor, $\mathrm{P}_{\text {comp, }}$, was derived from the total heat load (1) using a calculated coefficient of performance (COP) (29). The COP of the refrigeration system was calculated using the formula given in Cleland (1994) (30). 


$$
\begin{gathered}
P_{\text {comp }}=\frac{Q_{T}}{C O P} \\
C O P=\frac{\left(273+T_{e}\right) \cdot(1-\alpha \cdot x)^{n} \mu_{c o m p}}{\left(T_{c}-T_{e}\right)}
\end{gathered}
$$

The evaporating temperature, $\mathrm{T}_{\mathrm{e}}$ was set to be $7 \mathrm{~K}$ lower than the room temperature. The condensing temperature, $\mathrm{T}_{\mathrm{c}}$ was set to be $15 \mathrm{~K}$ higher than outside dry bulb temperature.

The electrical power of the condenser and evaporator fan motors, $\mathrm{P}_{\mathrm{mc}}$ and $\mathrm{P}_{\mathrm{me}}$ were derived from their shaft power and efficiency (31).

$$
P_{m c, m e}=\frac{S}{\mu}
$$

For electric defrosts, the electrical power of the defrost heater was equal to the amount of heat required to melt all the condensed and frozen water which entered the room through the doorway and from product/packaging divided by the efficiency of defrost (32). If the defrost was set to hot gas or natural, the defrost electrical energy $\mathrm{P}_{\mathrm{de}}=0$.

$$
P_{d e}=\frac{\left\lfloor m_{a d}\left(X_{o}-X_{i}\right) \cdot l . t . N_{d o, 24}\right\rfloor+\left(m_{w a t} l\right)}{\mu_{d e}(24.3600)}
$$

The total calculated heat load and electrical power during the day and year were presented as line and bar graphs. An example of the electrical consumption output sheet is shown in Figure 2. 

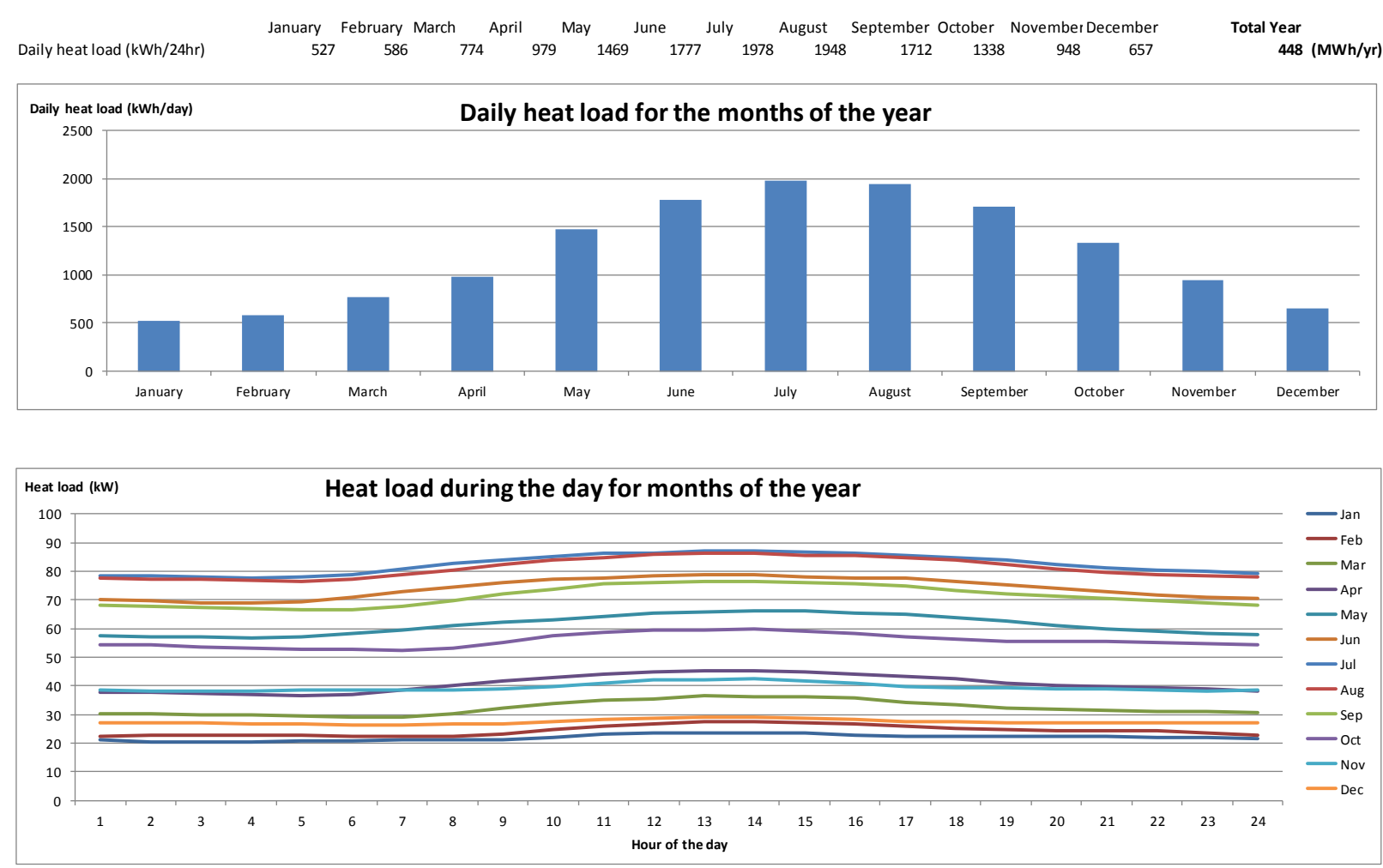

Figure 2. Electrical power output screen for the model

\section{METHOD}

\subsection{Verification}

Verification on a real refrigeration system is very difficult as many of the input variables cannot be controlled with sufficient accuracy to provide a meaningful validation. Therefore the model results were verified against those from CoolPack V1.5 toolkit, an industry standard refrigeration model.

The transmission load was calculated and compared with that calculated by CoolPack for the same size cold store with the same boundary conditions. The cold store was one of the cold stores audited in the ICE-E project (Evans et al, 2013). It had dimensions of $58.5 \times 68 \times 11 \mathrm{~m}$. It had an internal temperature of $3.0^{\circ} \mathrm{C}$. Three of the 4 walls and ceiling had an external temperature of $17^{\circ} \mathrm{C}$ and one of $5^{\circ} \mathrm{C}$. The floor had an external temperature of $12^{\circ} \mathrm{C}$. $\mathrm{U}$ values of the walls and ceiling were $0.23 \mathrm{~W} \cdot \mathrm{m}^{-2} \cdot \mathrm{K}^{-1}$ and the floor $0.98 \mathrm{~W} \cdot \mathrm{m}^{-2} \cdot \mathrm{K}^{-1}$ 


\subsection{Effect of ambient conditions}

The effect of ambient conditions (from the weather data) was evaluated on an identical cold store in 3 different worldwide locations for a year. The cold store was of dimensions $60 \times 60 \times 10 \mathrm{~m}$ and had an internal temperature of $2^{\circ} \mathrm{C}$ and the locations were Parma (Italy), Aberdeen (UK) and Guangzhou (China). Further parameter details are shown in Figure 1. This was chosen as a typical chill store from a benchmarking survey of cold stores around the world (Evans et al 2014). A comparison was made of the transmission load when the walls were in shade (no solar effect). The effect of ambient conditions on the COP of the refrigeration plant was also evaluated. The condenser was air cooled using outside ambient air.

\subsection{Transient vs steady state model}

One of the benefits of the ICE-E model over steady state models is that it takes into account the transient nature of the ambient conditions and the effect on yearly heat load and COP.

It is possible to use a steady state model to predict the energy consumption over a year by calculating at a mean annual temperature or taking mean conditions over periods of less than a year e.g. a month.

To determine the impact of transient conditions the ICE-E model was used to predict COP using the following methods for the same cold store and in the same locations as those in Section 3.3;

Method 1. The sum of the hourly heat loads throughout the year was divided by the sum of the hourly power consumptions throughout the year (33).

$$
C O P_{\text {method } 1}=\frac{\sum_{i=1}^{8760} q_{T^{i}}}{\sum_{i=1}^{8760} P_{T^{i}}}
$$

where 8760 is the number of hours in a year.

Method 2. The COP was calculated at the mean annual temperature.

Method 3. The COP was calculated from the mean of the hourly COPs (34). 


$$
C O P_{\text {method3 }}=\frac{\sum_{i=1}^{8760} \frac{q_{T^{i}}}{P_{T^{i}}}}{8760}
$$

Method 4. The COP was calculated each month from average monthly temperatures and then averaged over the year (35).

$$
\operatorname{COP}_{\text {method } 4}=\frac{\sum_{i=1}^{12}\left(\frac{q_{T}}{P_{T}}\right)_{i}}{12}
$$

Method 5. The heat load and electrical power were calculated each month from average monthly temperatures and then totalled for the year. The total heat load was then divided by the total electrical power to give the COP (36).

$$
C O P_{\text {method } 5}=\frac{\sum_{i=1}^{12} q_{T^{i}}}{\sum_{i=1}^{12} P_{T^{i}}}
$$

\section{RESULTS}

\subsection{Verification}

Coolpack and the ICE-E model predicted a transmission load of $54.792 \mathrm{~kW}$ and $54.77 \mathrm{~kW}$ respectively, a difference of $0.04 \%$. This difference was expected to be due to numerical rounding.

The COP was calculated and compared with that calculated by CoolPack for a single stage DX evaporator cycle using R404A as the refrigerant. The evaporating temperature and condensing temperature were set to $-4.0^{\circ} \mathrm{C}$ and $32.0^{\circ} \mathrm{C}$ respectively. Default values for superheat, sub-cooling and pressure loss were set in CoolPack. Coolpack and the ICE-E model predicted a COP of 3.403 and 3.424 respectively, a difference of $0.6 \%$. 


\subsection{Effect of ambient conditions}

Figure 3 shows the heat load through transmission on the cold store for the months of the year at the different locations. Guangzhou has the highest heat load due its hot climate; however, it does not vary much during the year (63\% difference between coldest and warmest month). Parma has the largest difference in heat load between winter and summer conditions (783\% difference).

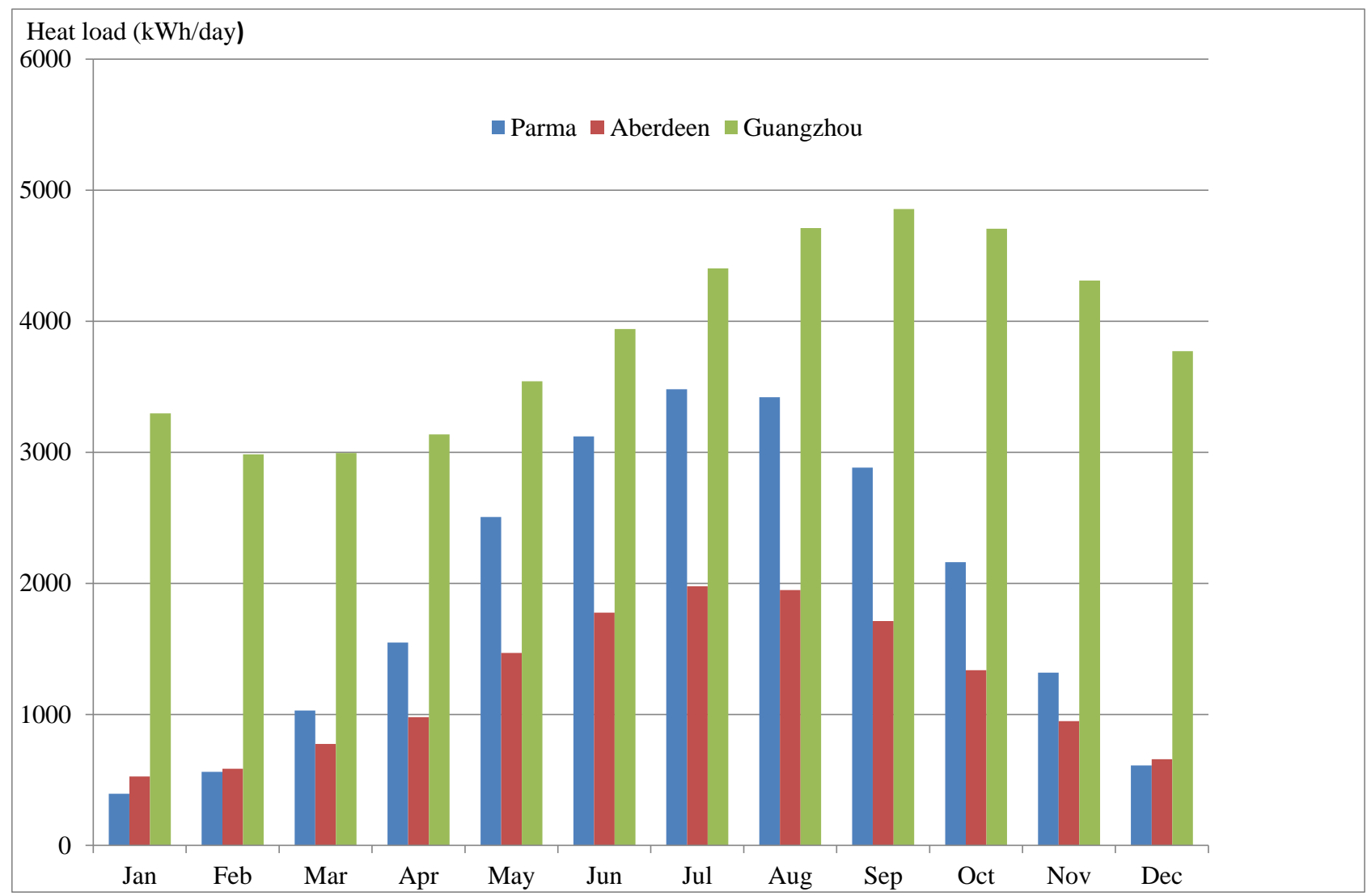

Figure 3. Heat load from transmission for a cold store for different months of the year at different locations.

Figure 4 shows the average COP for the months of the year at the different locations. The effect on COP is similar to that for the heat load, with the warmest climate (Guangzhou) having the lowest COP and the largest range of COP being for Parma. For Guangzhou the COP drops by a maximum of $40 \%$ throughout the year, for Parma it drops by $59 \%$. 


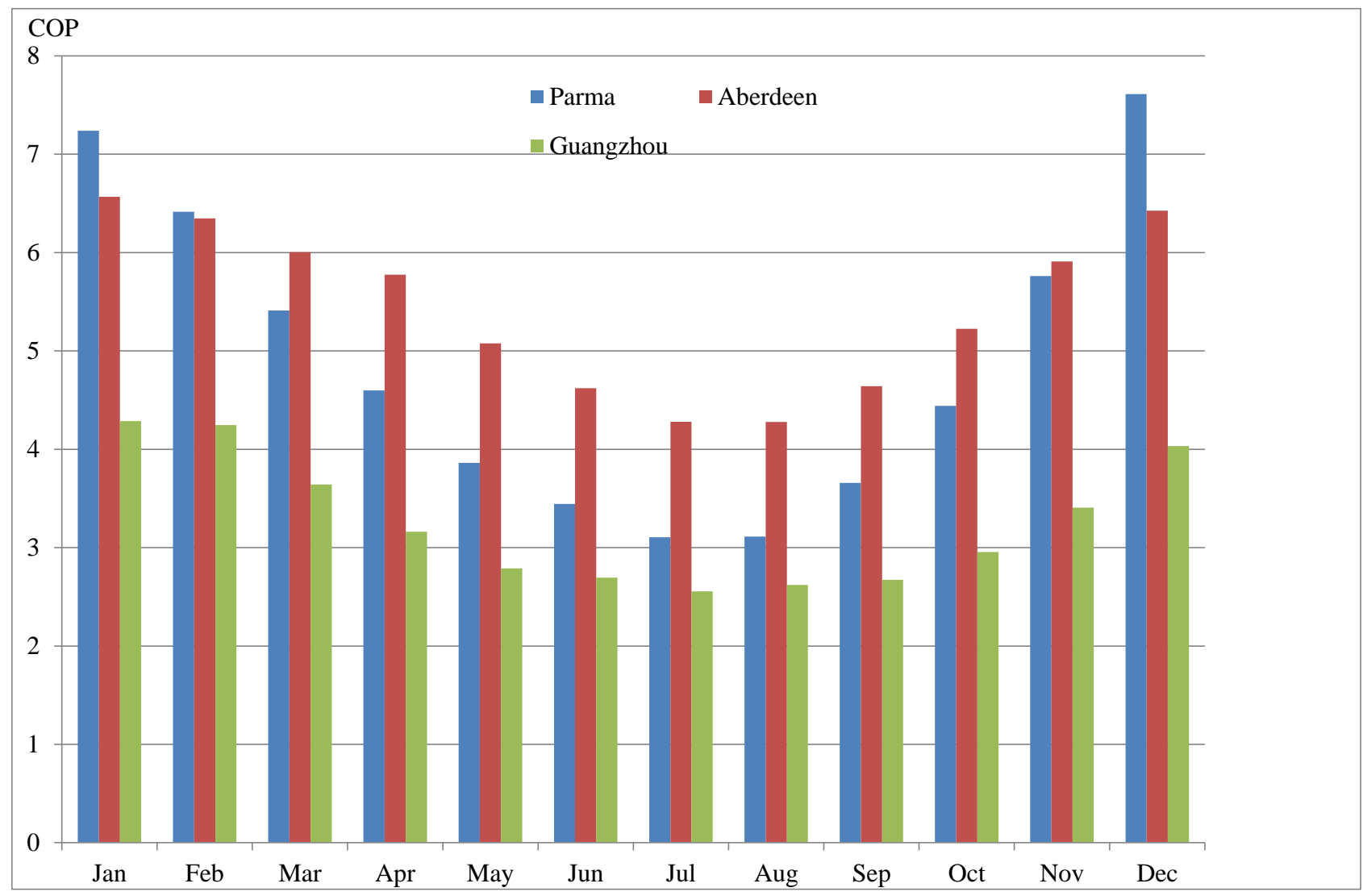

Figure 4. Average COP for a cold store refrigeration plant for different months of the year at different locations.

Figure 5 shows heat load and COP during a day in July. It can be seen that both heat load and COP fluctuate through the day with peak heat load and minimum COP at mid-afternoon and minimum heat load and maximum COP at early morning. In Parma the heat load fluctuates by $10 \%$ during the day, whereas the COP fluctuates by $25 \%$. 


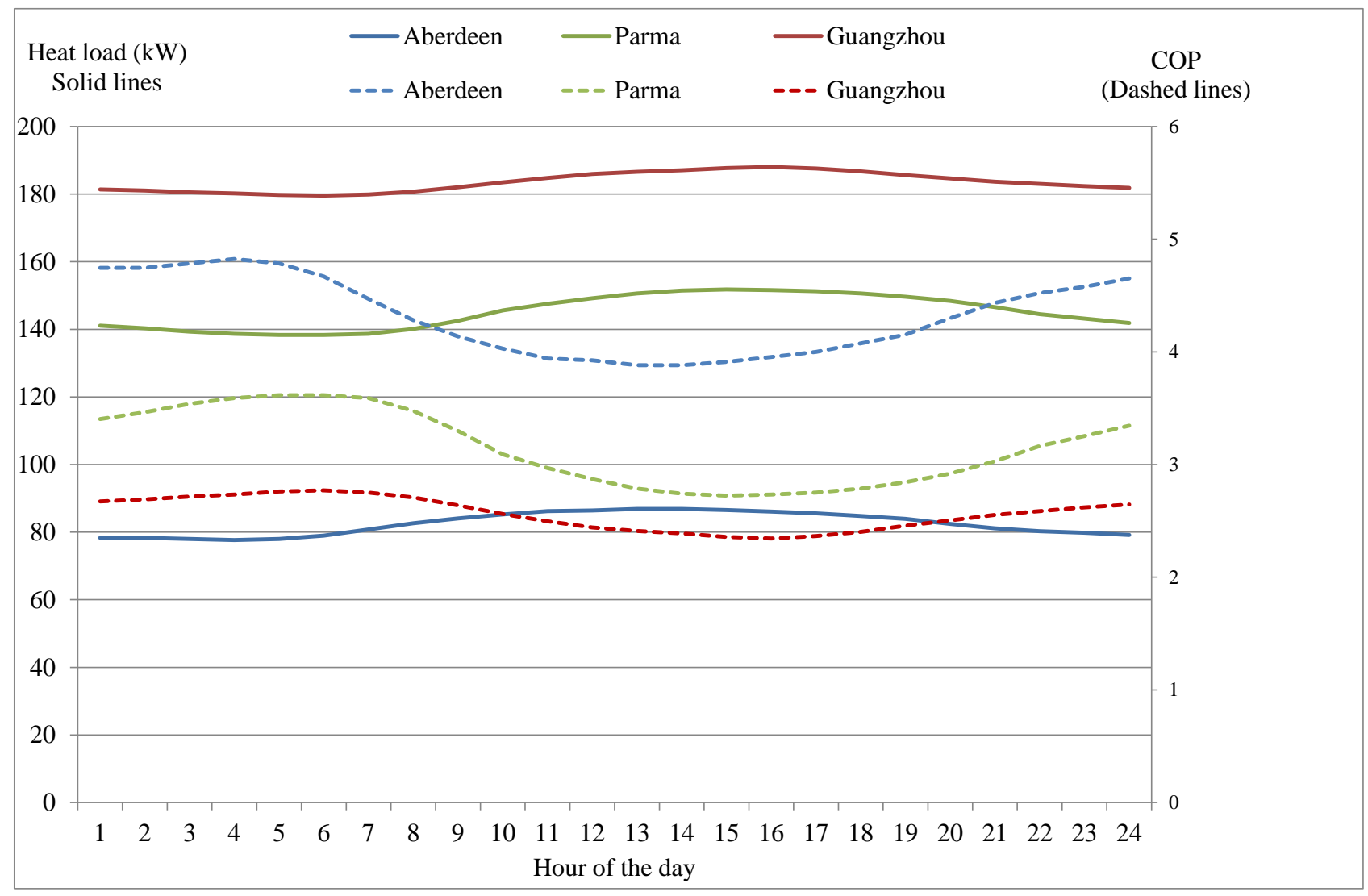

Figure 5. Heat load and COP during a day in July at each location.

A comparison was made of the transmission load when the walls (dark coloured) were in sunlight and in shade for the cold store in Parma. Overall the unshaded store had 4.5\% more transmission load over the year. The largest effect was in February with $6.9 \%$ more transmission load. The hour with the largest effect of solar radiation was 12:00-13:00 in February where the transmission load was $29.6 \%$ higher for the unshaded store. The actual increase in transmission load due to solar radiation is higher in the summer months, but as a proportion of the transmission load it is lower, as the winter transmission load is low.

\subsection{Transient vs steady state model}

Figure 6 shows the COP predicted by 5 methods for a cold store at 3 different locations; 


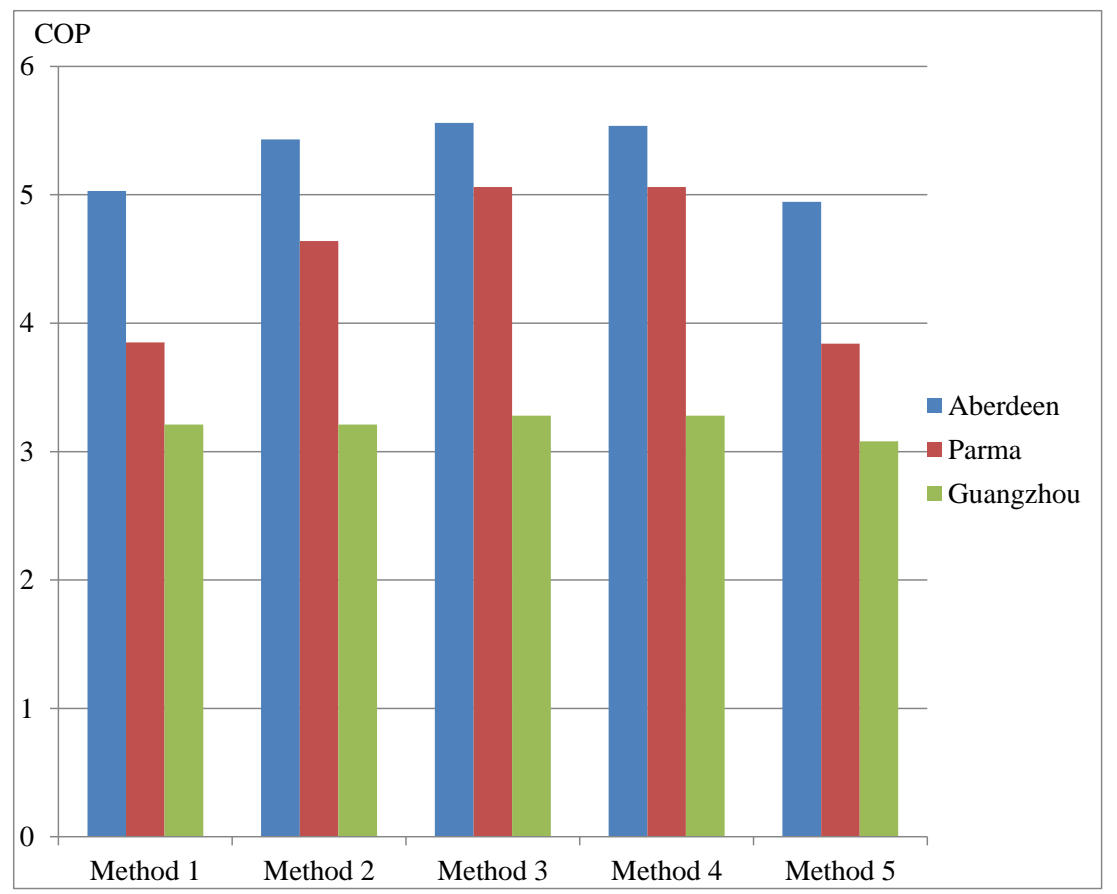

Figure 6. COP of a cold store in different locations calculated by different methods.

There is a difference in the COP from the different methods and a different effect at different locations. Using Method 1 as the baseline; Method 2 overestimates the COP by 25\%, $8 \%$ and $0 \%$ for the Parma, Aberdeen and Guangzhou locations respectively. Using Method 3 overestimates the COP even more, by $31 \%, 11 \%$ and $2 \%$ for the Parma, Aberdeen and Guangzhou locations respectively. Method 4 gives an almost identical answer to Method 3. Method 5 gives the most similar values underestimating by $0.3 \%$, $1.7 \%$ and $4.0 \%$. The difference between the methods is more pronounced where the heat load is more variable (Parma) and less pronounced where the heat load varies least (Guangzhou).

\section{CONCLUSIONS}

The ICE-E model is a freely available simple-to-use tool which allows cold store operators to investigate energy saving measures for their cold stores. When used by non-technical cold store operators it has advantages over the CoolPack model, as it does not require knowledge of $U$ values, air change rates, respiration rates, condensing and evaporating temperatures.

The ICE-E model allows technologies such as fans and lights to be investigated by changing their efficacy or efficiency. Required defrost energy is calculated, which allows the user to compare to actual defrost energy. 
It also allows the effect of door opening to be considered, as it calculates the effect of door opening frequency and time on both the sensible and latent load with and without door protection.

An important advantage of the ICE-E model over the CoolPack model is that it allows the heat load and energy consumption variation over the day and year to be shown. This can be useful to see whether there are times when peak heat loads may be too high for the capacity of the refrigeration plant.

When using a mean ambient temperature for the year, the COP was over-predicted by $25 \%$ for a location such as Parma. However, for a region such as Guangzhou (where fluctuations in ambient temperature are lower) the prediction is accurate. The ICE-E models hourly approach provides a much more satisfactory prediction than using the annual or monthly mean data in steady state simulations.

There were some disadvantages compared with the CoolPack model, related to the product load. The ICE-E model was designed for cold store use where product heat load was not high. Therefore the assumption was made that the product reached equilibrium in a day. However, this may not always be the case and the facility to enter the cooling time would be a useful additional feature which should be added to a later version. The ability to load more than one type of product and also to calculate product latent heat is an advantage over the ICE-E model. However the ICE-E model has a far larger database of product types and includes a value for thermal properties of mixed food cold stores. Further updates of the ICE-E model should allow the ability to freeze/thaw product and to add a variety of different products into the cold store.

\section{ACKNOWLEDGEMENTS}

The authors would like to thank EACI (Executive Agency for Competitiveness and Innovation) for funding this work.

The ICE-E model is freely available at the ICE-E website http://www.khlim-inet.be/drupalice/models. The model is available in the English, Italian, Dutch, Czech, Bulgarian and Danish languages.

\section{REFERENCES}

1. ETSU, 1994.Energy Consumption Guide 37: Cold storage sector. Energy Efficiency office, Department of the Environment, UK. 
2. ASHRAE. 2001. ASHRAE Fundamentals. Chapter 2 - Heat Transfer.

3. ASHRAE. 2006a. ASHRAE Refrigeration. Chapter 13 - 13. Refrigeration load.

4. ASHRAE. 2006b. ASHRAE Refrigeration. Chapter 9 - Thermal properties of food.

5. US-DOE. EnergyPlus. 2010 EnergyPlus Engineering Reference Manual, US Department of Energy http://apps1.eere.energy.gov/buildings/energyplus/pdfs/gettingstarted.pdf

6. Arias, J., Lundqvist, P., Sawalha, S., Axel, M. 2010. Advanced Modeling and Tools for Analysis of Energy Use in Supermarket Systems. Proceedings of the 1st IIR International Conference on Sustainability and the Cold Chain. Paris, France.

7. Baxter, V.D. 2003, IEA Annex 26: Advanced supermarket refrigeration/heat recovery system. Technical report, IEA.

8. Becker, B.R., Brian, P.E., Fricke, B. A., Sartin, B.C. 2012. Performance standards for walk in refrigerator and freezer systems. Air-Conditioning, Heating And Refrigeration Technology Institute, Inc. Report No. 09002-01. Virginia, USA.

9. Bosma, J. 1995. Inventory study of the energy conservation potential in cold storage insulations in the Netherlands, in Proc. 19th International Congress of Refrigeration, vol. II, 382-391.

10. Chen, P., Cleland, D.J., Lovatt, S.J., Bassett, M.R. 2002. An empirical model for predicting air infiltration into refrigerated stores through doors, Int. J. Refrigeration. 25;6, 799-812.

11. Cleland, A.C. 1994. Polynomial curve-fits for refrigerant thermodynamic properties: extension to include R134a., Rev. Int. Froid. 17;4, 245-249.

12. Cleland, D.J. 2011. The effect of water vapour on food refrigeration Systems. Proc. Inst. R. 201112. 5-1.

13. Elleson J.S., Freund, S.W. 2004. Benchmarking the Energy Performance of Industrial Refrigeration Systems, Interim Draft Report, Industrial Refrigeration Consortium, College of Engineering, University of Wisconsin- Madison, US. 
14. Evans, J.A., Hammond, E.C., Gigiel, A.J., Reinholdt, L., Fikiin, K., Zilio, C. 2013. Improving the energy performance of cold stores. Proceedings of the 2nd IIR Conference on Sustainability and the Cold Chain, Paris, France.

15. Evans, J.A., Foster, A.M., Huet, J.M., Reinholdt, L., Fikiin. K., Zilios, C., Houska, M., Landfeld, A., Bond, C., Scheurs, M., van Sambeeck, T.W.M. Specific energy consumption values for various refrigerated food cold stores. Energy and Buildings 74 (2014) 141-151.

16. Ge, Y.T., Tassou, S.A. 2000. Mathematical modelling of supermarket refrigeration systems for design, energy prediction and control. In: Proceedings of the Institution of Mechanical Engineers, Part A: Journal of Power and Energy, 214;2.

17. Getu, H.M., Bansal, P.K. 2006. Simulation model of a low-temperature supermarket refrigeration system. $H V A C \& R$ Research, 12;4, 1117-1139.

18. Gosney WB, Olama HAL. Heat and enthalpy gains through cold room doorways. Proc. Inst. of Refrig. 1975;72;31-41.

19. McAdams, W.H. 1954. Heat Transmission, $3^{\text {rd }}$ ed. McGraw Hill, New York.

20. Miles, C.A., Van Beek, G., Veerkamp, C.H. 1983. Calculation of thermophysical properties of foods. In: Physical Properties of Foods,. Jowitt, R., et al. (Eds), Elsevier Applied Science Publishers, London. Pp 103-122.

21. Mudgal, S., Tinetti, B., Bain, J., Cervantes, R., de Prado Trigo, A. 2011. Preparatory study for Ecodesign requirements for EuPs, Lot 1. Task 2: Economic and market analysis.

22. Natural Resources Canada, RETScreen International. http://www.retscreen.net/ang/home.php

23. IPU, Coolpack and Pack Calculation. Download from http://en.ipu.dk/Indhold/refrigeration-andenergy-technology/coolpack.aspx

24. Saint Trofee, The Netherlands. http://www.nightwind.eu/retail-refrigeration.html.

25. Singh, R.P. 2006. Benchmarking study of the refrigerated warehousing sector in California, Public Interest Energy Research Program, California Energy Commission. 
26. Werner, S.R., Vaino, F., Merts, I., Cleland, D.J. 2006. Energy use in the New Zealand cold storage industry, in IIR-IRHACE Conference, Auckland. NZ. 